\title{
Correction to: Adjusted tight control blood glucose management in diabetic patients undergoing on pump coronary artery bypass graft. A randomized clinical trial
}

\author{
Fatemeh Javaherforoosh zadeh ${ }^{1} \cdot$ Simin Azemati $^{2}$
}

Published online: 7 February 2020

(C) Springer Nature Switzerland AG 2020

\section{Correction to: Journal of Diabetes \& Metabolic Disorders} https://doi.org/10.1007/s40200-020-00494-4

The article 'Adjusted tight control blood glucose management in diabetic patients undergoing on pump coronary artery bypass graft. A randomized clinical trial', written by Fatemeh Javaherforoosh zadeh and Simin Azemati, was originally published electronically on the publisher's internet portal (currently SpringerLink) on 20th January 2020 with open access. With the author(s)' decision to step back from Open Choice, the copyright of the article changed on 10th February 2020 to (C) Springer Nature Switzerland AG 2020 and the article is forthwith distributed under the terms of copyright.

The original article has been corrected.

The online version of the original article can be found at https://doi.org/ 10.1007/s40200-020-00494-4

Fatemeh Javaherforoosh zadeh

f_javaherforoosh@yahoo.com

1 Department of Anesthesia, Ahvaz Anesthesiology and Pain Research Center, Ahvaz Jundishapur University of Medical Sciences,

Ahvaz, Iran

2 Anesthesiology and Critical Care Research Center, Shiraz University of Medical Sciences, Shiraz, Iran 